Essay Award was given to Peter Chiu of the Stanford University School of Medicine, California, for "Neurological Injury at Presentation Should Not Preclude Immediate Repair of Acute Type A Aortic Dissection."

The 2018-2019 Officers elected during the meeting include: President Patricia A. Thistlethwaite, La Jolla, California; Vice President Richard I. Whyte, Boston, Massachusetts; Secretary Sean C. Grondin, Calgary, Alberta; Treasurer Jessica S. Donington, Chicago, Illinois; Councilor Ross M. Bremner, Phoenix, Arizona; Councilor-at-Large Daniel L. Serna, Claremont, California; Historian Douglas E. Wood, Seattle, Washington; and Editor Richard D. Weisel, Toronto, Ontario.

Also during the 44th Annual Meeting, 22 new members were elected to WTSA membership-16 to Active membership and 6 to Candidate membership: Muhammad Aftab, Aurora, Colorado; Shair U. Ahmed, Phoenix, Arizona; Douglas C. Appleby, Salt Lake City, Utah; Awais Ashfaq (Candidate), Portland, Oregon; Peyman Benharash, Los Angeles, California; Zachary E. Brewer (Candidate), Reno, Nevada; Sergio Alejandro A. Carrillo, Las Vegas, Nevada; Edward Y. Chan, Houston, Texas; Hannah Copeland, Jackson, Mississippi; Paul W. Fedak, Calgary, Alberta; Eric R. Griffiths, Salt Lake City, Utah; Jessica Heimes (Candidate), Kansas City, Missouri; Toshinobu Kazui, Tucson, Arizona; Anthony W. Kim, Los Angeles, California; Madhankumar Kuppusamy, Seattle, Washington; Douglas Z. Liou (Candidate), Stanford, California; Sarah Z. Minasyan, Fresno, California; Sameh M. Said, Rochester, Minnesota; Joseph D. Schmoker, Missoula, Montana; John R. Stringham (Candidate), Salt Lake City, Utah; Dustin M. Walters, Charlottesville, Virginia; and Sean C. Wightman (Candidate), Stanford, California.

\section{WTSA Traveling Fellowship for Residents, Trainees, and Practicing Surgeons}

The goal of this traveling fellowship is to promote interaction and learning between residents/trainees/practicing surgeons and WTSA members. The traveling fellow will visit a University-affiliated or academic practice of his/her choosing, within the boundaries of the WTSA (Alaska, Arizona, California, Colorado, Hawaii, Idaho, Montana, Nevada, New Mexico, Oregon, Utah, Washington, and Wyoming, along with Canadian provinces of Alberta, British Columbia, Manitoba, and Saskatchewan), for a period of one to two weeks, under the sponsorship of a Western member at the hosting institution. The traveling fellow does not need to be a WTSA member; the award is open to any resident/trainee/practicing surgeon. More details are available at westernthoracic.org.

\section{Applications for WTSA Membership}

The WTSA is now accepting Applications for Membership online for Active as well as Candidate membership status for the 2019 membership cycle. Visit the WTSA Web site at www.westernthoracic.org to read the complete membership eligibility requirements and to initiate an online application.

\section{Active Member}

$\$ 375.00$ annually, plus \$50.00 initiation fee Applicant must meet all membership criteria, including but not limited to:

- Reside within or have completed a cardiothoracic residency training program within the geographic limits of the Association.

- Have been engaged in the practice of thoracic and cardiovascular surgery for at least three years following completion of postgraduate training. If a candidate completed his/her thoracic surgical residency or a one-year clinical fellowship in an institution within the geographic limits of the Association, such completion may count toward one of the three years of practice.

- Have a full and unrestricted license to practice medicine in his or her respective state or province, and have a current appointment on the surgical staff of a hospital with no reportable action pending which could adversely affect such applicant's staff privileges at any hospital.

\section{Candidate Member}

$\$ 100.00$ annually

Applicant must meet all membership criteria, including but not limited to:

- Be matched or enrolled in either a cardiothoracic surgery education program accredited by the Residency Review Committee for Thoracic Surgery under the authority of the ACGME or a program approved for cardiothoracic surgery education by the Royal College of Surgeons of Canada-or their equivalency-from within the Association's geographic limits. Individuals who have completed their education in one of the above programs but do not yet meet all of the criteria for Active membership also are eligible to apply for Candidate membership. Individuals who trained outside the Association's geographic limits who are now 
residing within the Association's boundaries but do not yet have three years in practice may also apply for Candidate membership.

An application must include the following uploads: a photo, a complete curriculum vitae with bibliography, and, for Active applicants, the 3 most significant articles that $\mathrm{s} /$ he personally wrote. The application must be completed and submitted online by March 1, 2019, and all support letter(s) (three for Active applicants, one for Candidates) uploaded by that applicant's sponsor(s) by March 31, 2019, in order for the applicant to be considered for election to membership at the 2019 Annual Meeting.

\section{WTSA 45th Annual Meeting}

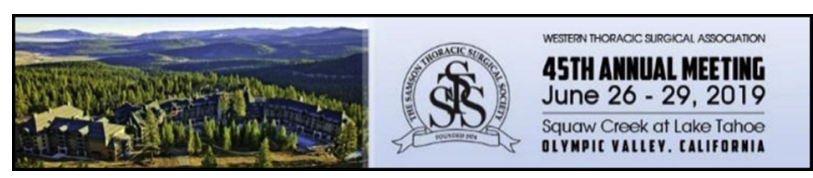

Save the Date!

June 26-29, 2019

Squaw Creek at Lake Tahoe

Olympic Valley, California
The American Board of Thoracic Surgery's Maintenance of Certification program was adopted 9 years ago. Since that time, there has been a continuous evaluation in the Board's thinking about the overall process, based upon internal discussions and input from our Diplomates.

These inputs resulted in our decision to migrate from a purely knowledge-based multiple-choice exam, using a Pearson Testing Center, to a Mastery Learning Process, using a SESATS format. Diplomates, enrolled in the 10-year MOC process, will fulfill their Part III requirement by completion of a home or office-based learning exam, following the instructions on the ABTS Web site.

There are 100 SESATS questions (primarily taken from SESATS XI), based on your specialty designation (Adult Cardiac, General Thoracic, Cardiothoracic, and Congenital), that you will need to work through as instructed. The exam will now be modular and tailored to your practice-for example, if your practice is $100 \%$ adult cardiac, you will only have adult cardiac and critical care questions. You will be able to take the 100-question exam anytime during the months of September and October. For those Diplomates who have used SESATS in the past, the process of working through the questions is the same. For those who are not familiar with SESATS, it might be beneficial to purchase and download SESATS and work through the specialty-specific module. This preparation will give you familiarity with the process. While SESATS may be helpful preparation, it is not required.

The goal of this exam is to provide a learning opportunity using judgement and decision making as well as knowledge. The Board and MOC Committee believe that reading the critique is key to the learning process using SESATS. The Board sincerely hopes that this new MOC Exam format that promotes life-long learning is viewed favorably by our Diplomates.

Everyone at the ABTS thanks you for embracing the primary principle of MOC-life-long learning, which is consistent with our obligation to the public trust.

\section{ABTS Requirements for the 10-Year Milestone for Maintenance of Certification}

Diplomates of the American Board of Thoracic Surgery (ABTS) who plan to participate in the 10-Year Milestone for the Maintenance of Certification (MOC) process as Certified-Active must hold a currently valid, full, and unrestricted license to practice medicine. Diplomates must have privileges at a hospital(s) accredited by the JCAHO or other institutions judged acceptable by the Board. Diplomates must also submit letter(s) of reference documenting their level of clinical activity and stature within the surgical community from the VP of Medical Affairs and one other responsible member on staff at their principal hospital. In addition, a valid ABTS certificate is an absolute requirement for entrance into the MOC process. Details on how to renew a lapsed certificate can be found on the Board's Web site at www.abts.org.

The CME requirements are 150 Category I credits over a five-year period. At least half of these CME hours need to be in the broad area of thoracic surgery. Category II credits are not accepted. Interested individuals should refer to the Board's Web site (www.abts.org) for a complete description of acceptable CME credits. 